\title{
A diversidade linguística e cultural em contextos escolares diversos
}

\section{Linguistic and cultural diversity in divers school contexts}

\author{
Clarice Nadir von Borstel ${ }^{1}$ \\ Unioeste
}

Resumo: A abordagem em questão se faz sob a perspectiva de estudos pautados na Etnografia Escolar que se voltam para cenários plurilíngues/multiculturais complexos. Interessam a este estudo situações enunciativas em que se observam o bilinguismo e o bidialetalismo no cenário escolar, especificamente em comunidades de fala de minorias em contextos de salas de aula diversos, nos quais interagem as múltiplas identidades. Este estudo também se propõe a indicar caminhos para interpretar as formas linguísticas diglóssicas e os fatores socioculturais inerentes aos cenários de sala de aula que emergem de comunidades de fala de origens étnicas e de cultura rurbana, de acordo com o suporte teórico-metodológico de Erickson (1988, 1990, 2001), Gumperz (1991) e Bortoni-Ricardo (2004), enfatizando o ensino da diversidade e da cultura, sobre a necessidade de políticas linguísticas voltadas para as práticas pedagógicas. O caráter linguístico e sociocultural no Brasil tem sido objeto de estudos sobre línguas em e de contato, quais sejam: as línguas autóctones, alóctones, de fronteiras e de surdos, considerando-se a diversidade linguística e cultural. Nesse contexto, tomam espaços ainda de forma tímida políticas linguísticas e educacionais que considerem tais identidades.

Palavras-chave: Etnografia Escolar. Comunidades de fala. Fatores linguísticoculturais.

\begin{abstract}
The approach in question is made through the study perspective of School Ethnography research in complex plurilingual/multicultural scenarios, presenting how are investigated enunciative situations about bilingualism and bidialectalism in the school scenario in minority speech communities in diverse classroom contexts, in which multiple identities interact. The linguistic and sociocultural character in Brazil has been a study object about languages in and of contact be them autochthonous, allochthonous, border or deafs' languages, about linguistic-cultural diversity, gaining, timidly, space in school contexts in need of linguistic and educational policies. Besides indicating ways to interpret diglossic linguistic forms and the sociocultural factors inherent to these classroom scenarios, of speech communities of ethnical origin and rurban culture, according to the theoretical-methodological support of Erickson (1988, 1990, 2001), Gumperz (1991) and Bortoni-Ricardo (2004), highlighting the teaching of diversity, culture and linguistic policies in pedagogical practices.
\end{abstract}

Keywords: School Ethnography. Speech communities. linguistic-cultural aspects.
${ }^{1}$ Professora Doutora do Curso de Letras e do Programa de Pós-Graduação Stricto Sensu em Letras da Universidade Estadual do Oeste do Paraná Unioeste - Campus de Marechal Cândido Rondon, PR. E-mail: clavonborstel@gmail.com. 


\section{Introdução}

Para poder investigar situações enunciativas do bilinguismo e da diversidade linguística de comunidades de fala que emergem em contexto escolar de grupos minoritários - imigrantes, indígenas, moradores de fronteiras geográficas e surdos -, faz-se necessário definir percursos metodológicos e instrumentos de pesquisa que contribuam para tal abordagem. Assim, recorre-se aos aportes teóricos da Etnografia Escolar para discutir e repensar o saber de investigação de um dado corpus, tendo como enfoque o Estudo de Casos.

Desde o final dos anos 1960, pesquisadores ligados à Etnografia da Comunicação - como Dell Hymes, Susan Philips, John Gumperz e Frederick Erickson - propõem investigações em contextos de sala de aula com foco em alunos provenientes de grupos minoritários, com o objetivo de observar fatores como: a diferença do estilo da comunicação, as diferenças culturais, as falhas de compreensão na comunicação oral e as falhas na interação comunicativa entre professores e alunos, bem como o estigma relacionado à variante utilizada por esses alunos.

Nesse contexto, em que os usuários desses grupos de falantes interagem - na esfera profissional, religiosa e social de maneira geral - de uma forma societal com falares e escrita singulares, figura como orientação metodológica pertinente o Método da Etnografia Escolar (microetnografia).

Os propósitos essenciais dessa abordagem relacionam-se ao objetivo de documentar em detalhes o desenrolar dos eventos do cotidiano e de identificar os significados atribuídos a eles, tanto por aqueles que deles participam quanto por aqueles que os observam. A pesquisa envolve observação e participação de longo prazo no contexto de sala de aula (ambiente escolar) e sociocultural (societal).

A partir da abordagem etnográfica, é possível focar o Estudo de Caso, ou seja, aplicar tal abordagem ao estudo de um caso investigado, que pode tanto envolver um único indivíduo quanto um dado grupo social e cultural, voltando os olhos para um contexto mais amplo, como é o caso do ambiente escolar.

Tendo em vista essa perspectiva de investigação, apresentam-se pesquisas - relacionadas à Linha de Pesquisa Práticas linguísticas, culturais e de ensino do Programa de Pós-Graduação em Letras da Universidade Estadual do Oeste do Paraná (Unioeste) - desenvolvidas in loco pela autora deste artigo e por alunos orientados pelo Grupo de Pesquisa Linguagem, Cultura e Ensino, nas quais se recorreu à abordagem acima referida para investigar o contexto escolar, sociocultural, familiar e religioso de que participam comunidades de línguas em e de contato. Esses estudos objetivam investigar a diversidade linguística de línguas autóctones, alóctones, de fronteiras e de surdos, que ganha, ainda timidamente, espaço nos contextos escolares e demanda políticas linguísticas e educacionais específicas. 


\section{Uma forma investigativa sobre a Etnografia Escolar}

Nessa discussão, objetiva-se mostrar como trabalhar a pesquisa Etnográfica Escolar no cenário escolar envolvendo direção, professores e alunos.

Considerando que os relatos da pesquisa etnográfica compreendem respostas às perguntas que alguém elaborou para a investigação, entende-se que boas perguntas que visam aos objetivos propostos devem ser o âmago da pesquisa.

Nos estudos de Erickson (1988, 1990, 2001), as perguntas a que se recorre para atingir os objetivos pretendidos são respondidas: 1) por meio da observação e da participação de longa duração da pesquisa, através da gravação, seja em áudio ou em vídeo; 2) por meio de entrevistas formais e informais com vistas a responder às perguntas que alguém elaborou; 3) por meio da coleta de dados que envolvem o observar e o perguntar.

Observar e perguntar podem envolver diferentes fontes e, ainda, diferentes tipos de dados: a) notas de campo escritas pelo observador; b) comentários das entrevistas; c) gravações que se tornam o ponto forte do levantamento de dados para a transcrição e para a descrição de comportamentos verbais e não verbais; d) documentos locais/nacionais oficiais ou não oficiais; e) materiais históricos e fotográficos. Compreende-se que um bom planejamento de coleta de dados envolve procedimentos variados: observação, entrevista, coleta de documentos e frequentes gravações.

Observa-se ainda que, na pesquisa etnográfica escolar, é possível propor análise dos dados investigados com base em notas de campo que são cruzadas e confirmadas com os dados de entrevistas e de documentos escritos com enfoques históricos (locais, nacionais e internacionais).

No que tange ao universo escolar, considera-se que ensinar e aprender envolvem processos interativos que requerem a participação de professores e alunos. Em outras palavras, a vida escolar bem sucedida depende, principalmente, de como os professores e alunos compartilham convenções sociais e hábitos culturais, o que lhes possibilitará saber, por exemplo, quem tem o direito de falar, bem como quando e como pode fazê-lo. Isso acontecendo, são criadas condições para que ocorra a aprendizagem. Conforme Gumperz (1991, p. 74), "a familiaridade com as sutilezas da organização social da sala de aula é uma pré-condição para obter acesso às oportunidades de aprendizagem”.

Nesse sentido, a abordagem etnográfica visa a mostrar como se dá a prática escolar cotidiana, recurso válido quando se procura encontrar alternativas de ensino e a aprendizagem em contextos socioculturais complexos.

Na pesquisa empírica da Etnografia Escolar, é importante observar a comunidade de fala. Para Erickson (1988), quando se observa um dado 
contexto escolar, também se pode resgatar certos dados sobre a Etnografia da Comunicação Social, podendo ser aplicados em pesquisas Sociolinguísticas (das relações entre língua e de grupos minoritários na sociedade), enfatizando os problemas do ensino de língua. Toma-se como centro de interesse a fala produzida em situações interativas naturais da vida cotidiana, significando-a sob o ponto de vista dos falantes, isto é, documentando-se o que "as pessoas realmente fazem ao falar" (ERICKSON, 1988, p. 82-83).

A pesquisa embasada no Método da Etnografia da Comunicação Social (macroetnografia) está voltada a grupos de falantes minoritários e/ou de base rural que interagem de uma forma societal a partir de seus falares singulares.

Para tanto, de acordo com Erickson (1988, 1990, 2001), a Etnografia da Comunicação Social e Escolar buscam responder às seguintes perguntas: a) O que está acontecendo aqui? b) O que significa, para professores e/ou educadores envolvidos, o que está acontecendo? c) Como esses acontecimentos estão organizados? d) Em que tempo e espaço histórico estão acontecendo? e) Está acontecendo o mesmo em algum outro local na sociedade?

Nas ações em sala de aula, visa-se ao caráter de familiaridade, ou seja, por meio da Etnografia, busca-se tornar o familiar estranho, problematizar o que parece comum, tornar visíveis e explícitas ações não percebidas e/ou implícitas na rotina do cotidiano.

Foca-se a atenção em falantes bilíngues que interagem de forma societal e cultural em contextos urbanos, os quais continuam a falar a sua língua materna vernácula em casa, na vizinhança, na igreja e muitas vezes nos locais de trabalhos e na comunidade de forma geral. A necessidade de interagir com o grupo majoritário em ambiente urbano manifesta-se na interlocução desses falantes, quer seja num bidialetalismo quer seja num bilinguismo societal e/ou relativo, que leve a reduções linguísticas significativas entre as variáveis de um dado sistema linguístico e/ou de dois códigos ou mais no contexto escolar.

Assim, de acordo com Gumperz,

A diversidade linguística funciona como recurso comunicativo nas interações verbais do cotidiano no sentido de que, numa conversação, os interlocutores - para categorizar eventos, inferir intenções e apreender expectativas sobre o que poderá ocorrer e sobre o que também poderia acontecer em seguida - se baseiam em conhecimento linguísticos às diferentes maneiras de falar (GUMPERZ, 1998, p. 99).

Para poder abordar a heterogeneidade linguística manifestada em interlocuções de falantes, é importante apresentar a noção de competência comunicativa, gramatical, sociolinguística e discursiva em uma dada comunidade de fala, conforme estudos propostos por Hymes (1967, 1972). A 
teoria da competência comunicativa apresentada pelo autor foi elaborada a partir de críticas sobre as lacunas existentes na teoria chomskiana de ‘competência’ e 'desempenho' linguísticos. Hymes $(1967,1972)$ propôs uma reformulação dos conceitos chomskianos e adicionou o termo 'comunicativo' ao termo 'competência', demonstrando, portanto, sua preocupação com o uso real da língua pelo falante, como ser social, em suas interlocuções.

Seguindo os estudos de Hymes sobre a competência comunicativa, Canale e Swain (1980) dividem-na em quatro subcategorias: gramatical (morfossintática e semântica); sociolinguística (escolhas no uso da língua); discursiva (coesão e coerência) e estratégica (habilidade para compensar a falta do léxico necessário em certas situações).

Ainda sobre essa discussão, Bachman (1990) vai além e apresenta novos termos: ele chama a competência comunicativa de 'habilidade linguística comunicativa', que divide em três categorias: a) competência estratégica; b) mecanismos psicofisiológicos; c) competência linguística. A competência linguística seria então dividida em duas categorias distintas: a organizativa, que trata da fonologia, da sintaxe, da semântica, e da pragmática, que é ainda dividida em duas subcategorias: ilocutiva e sociolinguística. A competência ilocutiva relaciona-se aos atos de fala e é dividida pelo autor considerando-se quatro funções: função ideativa (expressar significados a partir da experiência do mundo real); função manipulativa (influenciar); função heurística (usar a linguagem para aumentar o conhecimento) e função imaginativa (empregar a língua para a criação ou ampliação de mundo de forma estética ou humorística). Nessa perspectiva de análise, a competência sociolinguística compreende: sensibilidade a dialetos, variedades e diferenças de registro e, ainda, naturalidade e habilidade para interpretar referências culturais.

Normalmente, os etnógrafos da comunicação assumem uma abordagem indutiva e empírica in loco, descrevendo a fala natural do indivíduo inserido em um grupo social na medida em que essa fala varia de falante para falante, de situação para situação. Nesse contexto, tendem a focar a gramática da língua, que funciona como conhecimento partilhado entre os falantes da comunidade de fala.

A Etnografia da Comunicação Social é, então, utilizada primeiramente para descrever as normas socioculturais e os valores dos grupos investigados que se mostram relevantes para o estudo da língua em uso, os quais dependem do contexto de que emergem, podendo variar de ambiente para ambiente, de região para região de um país. Para tanto, são observadas características como a estrutura sequencial da fala e os papéis dos participantes, seus direitos e deveres respeitados em termos de códigos linguísticos e da comunicação empregada pelos falantes.

Para descrever um Estudo de Caso etnográfico na área da Sociolinguística sob o viés da Pragmática, com foco em um dado grupo de uma 
comunidade de fala, há técnicas de pesquisa de campo que são básicas para a coleta de dados: 1) a observação e a participação, procedimentos propostos por Gumperz (1964a, 1964b, 1991, 1998), que os utilizou para obter amostras gravadas de interação de grupos bilíngues; 2) os roteiros de entrevistas com base nas pesquisas de Labov (1986), que combinou a técnica da observação e participação com roteiros de entrevistas em pesquisas de campo sobre a variação e/ou mudança linguística; e 3) o paradigma de redes de comunicação, conforme proposto por Barnes (1954, apud BORTONI-RICARDO, 1985).

Essas três técnicas de pesquisa de campo in loco foram utilizadas por von Borstel (1992, 1999, 2011) em estudo sobre o Brasildeutsch, uma variedade suprarregional do falar alemão (denominação que procura retratar a hibridização linguística de traços da língua padrão e de dialetos regionais alemães com o português), na comunidade de fala de Marechal Cândido Rondon e Entre Rios-Guarapuava, Paraná.

A partir dessas técnicas de pesquisa empírica in loco, os estudos de William Labov (1986) e Fernando Tarallo (1986) são discutidos e referenciados por von Borstel (2002/2003) com foco na Sociolinguística. Tendo como objeto de estudo a relação entre língua e sociedade, investiga-se o grau de estabilidade ou de mudança da variedade linguística em uma dada comunidade de fala, descrevendo seu comportamento preditivo, com base em teoria e métodos de estudos sociolinguísticos quantitativos que consideram os dados empíricos estatísticos - tanto em relação aos aspectos linguísticos internos à língua (fonologia, morfossintaxe, semântica) quanto no que tange às variáveis externas à língua (recursos pragmáticos, retóricos, socioculturais, geográficos, escolaridade, faixa etária, etnia, orientação religiosa, entre outros aspectos) - e qualitativos e/ou interpretativos, contribuindo para a interpretação de uma ou de outra variante das formas linguísticas em competição em uma comunidade de fala.

\section{A alternância de língua em contato em contextos escolares diversos}

Os discursos plurilíngues, considerados enunciações específicas de interação comunicativa de um ou mais códigos linguísticos, são utilizados nas interlocuções promovidas em contexto sociocultural de comunidades diglóssicas de línguas em contato quando há uma forte transferência linguística da língua materna vernácula para o português, conforme postulam estudos apresentados por Heye (2006) e von Borstel (2011) sobre o bilinguismo relativo e/ou situacional de dois códigos linguísticos De acordo com o exposto, observam-se e analisam-se esses traços linguísticos em contextos escolares, considerando-se a prática pedagógica promovida em sala de aula. 
Nas regiões interétnicas, a língua materna vernácula, saber partilhado que muitas vezes é revelado pelo processo psico-cognitivo-identitário de falantes bilíngues e bidialetais, constitui, no acervo do saber linguístico, principalmente, os traços fonológicos e o léxico semântico-pragmático de grupos de línguas autóctones, alóctones, de fronteiras e de surdos em contextos escolares.

Entende-se que o léxico de um dado grupo de fala configura a primeira via de acesso à comunicação verbal, uma vez que esse nível da língua é o que mais deixa transparecer os valores, as crenças, os hábitos e os costumes de comunidades de origens etnoculturais, assim como as inovações tecnológicas, as transformações socioeconômicas e as políticas que emergem na sociedade em que a língua majoritária é outra.

Desse modo, o universo das alternâncias linguísticas de grupos plurilíngues minoritários e multiculturais singulariza a maneira de ver a realidade e explicita como os falantes se comunicam com outrem, ainda que de forma estigmatizada pela sociedade. Assim, na medida em que esses traços linguísticos recortam realidades do grupo, definem, também, fatos presentes na comunidade de fala.

Estudos sobre a alternância linguística observada no processo inicial de alfabetização em comunidades de fala desses grupos não configura uma preocupação somente atual. Estudiosos da Linguística já se preocupavam, em outros tempos, com as transferências linguísticas das línguas autóctones, alóctones e de fronteiras no português. Dentre outros resultados, pontuam a necessidade de políticas linguísticas e educacionais no país.

Pesquisas realizadas em regiões de comunidades de imigrantes e/ou descendentes, de fronteira, de indígenas e de surdos têm sugerido, ainda, que questões linguísticas contribuem para o alto índice de evasão e repetência escolar em muitas escolas que atendem a alunos com esse perfil. A recorrência desse problema é observada mesmo com o esforço das Secretarias de Educação em desenvolver, ainda que timidamente, uma política educacional para poder resolvê-lo ou minimizá-lo, especialmente no que tange ao Ensino Básico.

Observa-se que, nas séries iniciais, muitas vezes os docentes não têm uma formação sobre a diversidade linguística, e muito menos sabem trabalhar os traços bilíngues da língua materna vernácula de seus alunos de uma forma fonológica e lexical.

A partir de 1986, houve a possibilidade de ensino de línguas minoritárias, como língua estrangeira, no Ensino Fundamental e Médio. Nesse contexto, em muitos casos, escolas optaram por compor o currículo com uma dessas línguas. Entretanto, não se tem conhecimento de estudos sistemáticos no país que tenham observado o resultado desse ensino no que diz respeito à extensão do bilinguismo dos alunos atendidos. 
Nesta época, de acordo com as condições para a criação de turmas, havia professores apenas para as línguas alemã, espanhola, francesa, inglesa e italiana. O objetivo do CELEM era:

o ensino instrumental da língua (aprendizado e aprofundamento), para aperfeiçoamento cultural e profissional dos estudantes, desenvolvendo neles especialmente as habilidades de leitura e interpretação de textos, oportunizando-se, aos alunos de melhor rendimento, o desenvolvimento da escrita e da fala. (Resolução Secretarial n 3.546/1986 de 15 de agosto de 1986)

É preciso pontuar que, no estado do Paraná, o CELEM (Centro de Estudos de Línguas Estrangeiras Modernas) figura como um programa criado pelo governo para enriquecer a formação bilíngue de alunos dos níveis Fundamental e Médio da rede pública estadual, por meio do ensino de línguas estrangeiras. Foi criado em 1986, fundamentado no artigo $7^{\circ}$ da Resolução Secretarial n 3.546/86, e posto em prática nas escolas a partir de 1988.

Os cursos relacionados a esse programa são ofertados nas escolas públicas estaduais. Os projetos devem ser aceitos e estruturados antecipadamente, abrangendo uma ou mais línguas, de acordo com a capacidade e estrutura da escola.

Entende-se que os cursos oferecidos pelo CELEM são importantes e oportunos por considerarem a variedade étnica/cultural do estado do Paraná. Conforme Auada (1993), o CELEM, ao levar em conta a composição étnica da população paranaense, busca "desenvolver cursos de língua e cultura alemã, francesa, hispânica, inglesa, italiana, japonesa, ucraniana, árabe, polonesa e hebraica, visando estimular e facilitar a inclusão dessas línguas nos currículos plenos do Sistema Educacional do Estado do Paraná” (AUADA, 1993, p. 20).

Infelizmente, há um número pequeno de alunos descendentes de imigrantes que participam do CELEM, como foi registrado na pesquisa de Mezavila (2007):

Quando iniciou o CELEM de língua ucraniana em Cascavel, havia trinta alunos matriculados. Porém, com o passar do tempo, aqueles que não eram descendentes de ucraniano e, portanto, não se identificavam com a cultura, com a língua, e não faziam parte da comunidade, desistiram. [...] o CELEM de língua ucraniana apresenta como interessados a comunidade ucraniana, em contraposição à comunidade escolar, pelo fato de essa língua não ter incentivo empregatício ou comercial. (MEZAVILA, 2007, p. 47).

De acordo com Mezavila, em 2007, quando fez a pesquisa, havia 22 alunos descendentes de ucranianos matriculados no curso de língua ucraniana no CELEM de Cascavel. 
O ensino de língua ucraniana pelo CELEM também é proposto em Prudentópolis, Irati, Dorizon, Curitiba e Rio Azul; porém, não se tem dados sobre a extensão do bilinguismo desses falantes de línguas alóctones. Observa-se que, como consequência de acordos entre os países do Mercosul, o ensino de espanhol como língua estrangeira ganha um status especial nos contextos de fronteira do Brasil com os países vizinhos. Além disso, o forte valor que se dá ao inglês como língua franca internacional resulta na escolha de muitas escolas pela inclusão dessa língua em suas grades curriculares, em detrimento das línguas minoritárias de imigrantes e de fronteiras.

\section{Estudos etnográficos escolares em contextos sociolinguísticos diversos}

As pesquisas etnográficas escolares aqui referenciadas têm como suporte teórico-metodológico os estudos de Etnografia Escolar de Erickson (1988, 2001), a Sociolinguística Interacional de Gumperz $(1998,1991)$ e a Sociolinguística Interacional/Educacional de Bortoni-Ricardo (2004).

Levando-se em conta as pesquisas desenvolvidas nas escolas, pode-se dizer que há uma sensibilidade por parte destas no tocante ao bilinguismo e ao bidialetalismo. No entanto, os próprios docentes sentem a necessidade de um trabalho de formação continuada para que, efetivamente, tenham acesso a instrumentos e práticas pedagógicas que lhes deem condições de trabalhar com o contexto sociolinguisticamente complexo, como ocorre nas escolas de comunidades de imigrantes e seus descendentes, de indígenas, de fronteira e de surdos.

Nesse sentido, buscam-se alternativas para as políticas linguísticas e educacionais voltadas a esses cenários socioculturais de competências comunicativas linguísticas. Reforça-se assim a ideia de que "a escola precisa tornar-se culturalmente sensível para poder lidar competentemente com a variação linguística e cultural de nossas crianças”, conforme analisam Bortoni-Ricardo e Detoni (2001, p. 81). Ainda de acordo com as autoras, é necessário considerar a multiplicidade linguística e as diferenças culturais no contexto escolar e no entorno social, de modo a contribuir de forma sensível para que, no âmbito pedagógico, sejam discutidos estudos sobre a heterogeneidade linguística.

O cenário plurilíngue presente nas regiões em que convivem brasileiros, paraguaios, argentinos, árabes, entre outros, além de imigrantes alemães, italianos, poloneses, ucranianos e seus descendentes, que participaram do processo de colonização da região, e demais migrantes advindos das mais diversas regiões do país, evidencia a persistência de uma multiplicidade linguística e cultural promovida por esses falantes. 
As discussões sobre línguas minoritárias em contato linguístico iniciaram-se com estudos etnográficos escolares do falar alemão-português de descendentes de imigrantes. Tendo como suporte esses estudos teórico-metodológicos sobre línguas em contato e Etnografia Escolar, von Borstel (1998) pesquisou, em escolas públicas e particulares da comunidade de Marechal Cândido Rondon, a variável interna fonológica da vibrante simples e múltipla em início de palavras, em posição intervocálica e no final de sílabas, e a variável externa à língua, considerando os seguintes fatores: escolaridade - processo inicial de alfabetização até a quarta série do Ensino Fundamental -, sexo/gênero e ascendência étnica alemã. Observou-se a transferência da alternância linguística na comunicação verbal (oral e escrita) de dialetos do falar alemão em sala de aula. Tal aspecto linguístico, assim como fatores extralinguísticos, ainda, se fazem presente nas interlocuções orais e verbais, tanto de alunos quanto de alguns docentes da comunidade.

Em 2002, von Borstel e dois docentes do Ensino Médio da rede pública trabalharam com produções escritas do vestibular/2002 da Unioeste, campus de Marechal Cândido Rondon, observando as transferências linguísticas de segmentos vocálicos e consonantais. São exemplos de transferências de consoantes observadas: a oclusiva velar e alveolar vozeada/ sonora pela desvozeada/surda; a fricativa alveopalatal vozeada/sonora pela desvozeada/surda; e, também, a fricativa alveolar desvozeada/sonora pela vozeada/surda. Verificou-se ainda uma forte variação de traços fônicos bilíngues do falar alemão-português e de itens lexicais de um contínuo rural-urbano, considerando-se a complexidade cognitiva envolvida nas marcas linguísticas de sintagmas verbais e nominais. Cabe ressaltar que foi observada, nesse estudo de textos escritos produzidos em comunidades de línguas em e de contato, a ocorrência de fortes indícios lexicais de transferências fônicas no que diz respeito aos fatores do cotidiano internalizado no processo cognitivo e sociopsicológico desses vestibulandos.

No período de 2002 a 2003, von Borstel desenvolveu pesquisa, intitulada Um estudo sobre os traços do talian na etnografia escolar, baseada na Etnografia Escolar, visando à observação das complexas relações de alternâncias linguísticas na comunicação verbal (oral e escrita) promovida por professor/alunos da $1^{a}$ série do Ensino Fundamental de uma escola pública de Palotina inserida em comunidade de fala italiana/portuguesa. Essa pesquisa foi descrita em forma de relatório, conforme o projeto de pesquisa, apresentado no Pós-Doutorado, na Universidade Estadual de Campinas, em março de 2004, sob a orientação de Marilda do Couto Cavalcanti. Parte desse estudo foi publicado por von Borstel (2011, p. 33-48) em um dos textos que compõem o livro Linguagem, Cultura e Ensino. Nesse texto, foram analisados traços fônicos e itens lexicais do talian (a hibridização do léxico e de traços fônicos de dialetos italianos com o português) visualizados em produções escritas, como é o caso das palavras "mama” (màmma: mãe) e 
"nona” (nònna: avó), entre outros itens lexicais e traços fonológicos do talian, observados, no ambiente escolar, nas interações comunicativas orais e escritas de 19 alunos descendentes de italianos.

A Etnografia Escolar também tomou parte de estudos realizados a partir de março de 2004, quando foram orientados alunos pelo Grupo de Pesquisa Linguagem, Cultura e Ensino do Programa de Mestrado em Letras da Unioeste.

Sob a concepção da Etnografia Escolar e da Sociolinguística, Teis (2004) apresentou um estudo de caso com alunos brasiguaios bilíngues - português/espanhol e português/espanhol/alemão - da comunidade de Itaipulândia, PR, fronteira geográfica do Brasil com o Paraguai. Nesse trabalho foi analisada a transferência da modalidade oral em textos escritos produzidos em sala de aula por alunos brasiguaios descendentes de alemães que viveram no Paraguai durante a infância e a adolescência. A pesquisadora constatou que os fatores culturais, cognitivos e sociopsicológicos desses alunos brasiguaios resultam de vivências do uso de mais de um código linguístico que marcam a comunicação, tanto na modalidade oral quanto na escrita, através de transferências orais materializadas no léxico em português. Para a autora, a fim de garantir a manutenção da dignidade, da identidade e do respeito ao indivíduo brasiguaio, é necessário que tanto a língua materna vernácula quanto à de herança cultural de origem étnica sejam reconhecidas, respeitadas e valorizadas.

Em 2006, Doebber, no trabalho intitulado Traços da língua materna vernácula no contexto escolar, investigou eventos de oralidade e letramento na $1^{\text {a }}$ e na $6^{\text {a }}$ série de duas escolas públicas de Pato Bragado, PR. O contexto desse estudo é de língua de imigrante alemã e também de fronteira geográfica Brasil/Paraguai. Os estudos etnográficos em sala de aula consideraram narrativas e entrevistas orais, que permitiram chegar à conclusão de que a língua materna vernácula dos alunos investigados é o Brasildeutsch. Doebber (2006) identificou a transferência de traços linguísticos da oralidade para a escrita do português e observou que tal característica resulta, muitas vezes, em traumas psicológicos e estigma identitário. Para a estudiosa, esses traços linguísticos podem ser trabalhados em sala de aula a partir de uma prática pedagógica linguística e multicultural crítica.

Ainda sobre línguas de fronteiras, cita-se a pesquisa intitulada Alunos brasiguaios em escola de fronteira Brasil/Paraguai: um estudo linguístico sobre aprendizagem do português em Ponta Porã, MS, de Dalinghaus (2009). O município foco de análise faz fronteira seca com Pedro Juan Caballero, Paraguai, e atende a cerca de $90 \%$ de alunos oriundos do país de fronteira. A autora analisou a relação plurilíngue dos alunos na escola com base em provas de classificação, avaliações em língua portuguesa, documentos, diário de campo e entrevista com os alunos. A pesquisa resultou na observação de que, mesmo já tendo sidas implantadas Escolas 
bilíngues de fronteira, as fronteiras culturais e linguísticas se transformam em barreiras para os alunos. A pesquisadora percebeu que, por vezes, adolescentes são impedidos de progredir na escolaridade em razão da falta de domínio do português padrão; assim, os alunos paraguaios, também denominados brasiguaios, tendem a retroagir no processo de escolaridade.

Com relação ao cenário indígena, Teis (2007) pesquisou a escrita e o letramento de alunos do grupo étnico-indígena avá-guarani, na Escola Rural Municipal Indígena Avá-Guarani, em Santa Rosa do Ocoí, localidade próximo à fronteira do Paraguai, no oeste paranaense. Segunda a pesquisadora, no contexto de sala de aula estudado, a língua indígena predomina na maior parte das interações entre os alunos indígenas, sendo o uso do português restrito à comunicação com os professores não índios ou com outras pessoas que não falam a língua guarani e, ainda, à realização das atividades escritas. A língua portuguesa corresponde à segunda língua desses alunos indígenas. Ainda segundo a estudiosa, a aprendizagem da língua portuguesa não resolve os conflitos que as diferenças de comunicação interétnica ocasionam. O estilo de comunicação indígena é marcado por escolhas formais e discursivas que têm origens ideológicas associadas às questões de identidade cultural; portanto, essas formas de comunicação precisam ser respeitadas, e não suplantadas pelo estilo de comunicação do branco.

No tocante ainda às línguas indígenas, cita-se também a pesquisa de Sales (2010), que estudou a organização e a reorganização do projeto político pedagógico de uma escola indígena em Dourados, MS. A escola estudada atende a alunos das etnias guarani, kaiowá e terena, com níveis diferenciados de proficiência oral em suas línguas maternas vernáculas e reflete esse ambiente de línguas indígenas, com docentes com níveis de proficiência heterogêneos. Existem aqueles professores que falam e leem em língua indígena, aqueles que somente falam e outros que entendem embora não falem a língua dos alunos e, ainda, os monolíngues em português, sem nenhuma habilidade com qualquer uma das línguas indígenas para poder interagir com os alunos de uma forma bilíngue.

Em relação ao contexto escolar de língua de surdos, Moura (2006) propôs estudo etnográfico sobre A representação dos ouvintes sobre o desenvolvimento do estudante surdo e as implicações na/pela linguagem. $\mathrm{O}$ estudo envolveu sujeitos surdos de duas escolas públicas estaduais uma de Marechal Cândido Rondon e outra de Toledo, com vistas à investigação do processo de aquisição do conhecimento por parte do sujeito surdo, assim como da aquisição dos processos discursivos da Língua Brasileira de Sinais (LIBRAS). Tomou-se como foco da análise textos narrativos, observando as redes de compreensão ideológicas. A partir das narrativas apresentadas pelos sujeitos surdos, a autora percebeu a constituição histórica na qual se apresentaram as múltiplas vozes que de fato auxiliam no arcabouço 
do conhecimento, formando um conjunto de representações e concepções para o desenvolvimento psíquico e cognitivo do sujeito surdo, refletindo na sua consciência social e identitária. De acordo com a pesquisadora, as interações comunicativas por meio da Língua Brasileira de Sinais, além de serem responsáveis pela composição ideológica do universo social de cada um desses estudantes, também norteiam a formação do gênero discursivo e, consequentemente, a construção da consciência individual e coletiva, resultando na bagagem das interações ideológicas presentes no cotidiano desses sujeitos surdos quando da utilização da LIBRAS com variações de sinais pelos usuários e seus familiares.

De acordo como o que foi descrito acerca das pesquisas desenvolvidas em contextos escolares sociolinguisticamente complexos, ainda é preciso fazer muito em sala de aula que abarca grupos minoritários, não se podendo deixar de lado a formação continuada e a reflexão sobre as práticas linguísticas bilíngues e as políticas linguísticas educacionais dos contextos etnográficos apresentados.

\section{Considerações finais}

Salienta-se que, em pesquisas sobre o ensino e a variação linguística em comunidades bilíngues/bidialetais de imigrantes, de indígenas, de fronteiras e de línguas de surdos, têm papel relevante os métodos de pesquisa de campo, tomando-se como suporte estudos direcionados pela Etnografia Escolar e pela Etnografia da Comunicação Social.

Pode-se responder, com base nessas pesquisas em contextos escolares diversos sobre a diversidade linguística e cultural em sala de aula, que é necessário mostrar o que está acontecendo nas práticas de ensino-aprendizagem em salas de aula para poder discutir como estão sendo interpretadas as políticas linguísticas e educacionais. Desta forma, observa-se a necessidade de se atuar e estar atentos às dificuldades das escolas em relação à formação continuada dos docentes no que tange aos estudos bilíngues e bidialetais, tendo como enfoque as práticas culturais, linguísticas e pedagógicas nesses contextos sociolinguisticamente complexos.

Pelo exposto, não se pode negar o importante papel que as políticas linguísticas vigentes no Brasil têm desempenhado em relação a questões de língua(s) e cultura(s) e suas implicações no ensino, no tocante a essas situações de variáveis linguísticas. Mas ainda é necessário ter conhecimento sobre a história, a realidade sociocultural, linguística e econômica desses grupos minoritários, sobre o fortalecimento linguístico das línguas de tais grupos e sobre a diversidade linguística cultural local.

O sistema diglóssico que abarca a diversidade de línguas autóctones, alóctones, de fronteiras e de surdos passa por mudanças constantes 
através do tempo e em relação ao espaço social e geográfico, principalmente no mundo moderno, que constantemente subverte a compartimentalização societal em favor da globalização.

Neste sentido, acredita-se que é necessário "preservar a diglossia de Ferguson para dar conta de um tipo específico de variação entre uma variedade 'A' e uma variedade ' $\mathrm{B}$ ', que é socialmente considerada como uma mesma língua”. Ou seja, “a primeira nunca é usada em comunicações ordinárias e informais, embora certa porcentagem dessa variedade 'A' possa ser utilizada, dependendo do domínio do sistema diglóssico por parte do falante” (HEYE, 2006, p. 80).

\section{Referências}

AUADA, Adel T. Realidade e perspectivas dos centros de línguas no estado do Paraná. In: EPLLE - ENCONTROS DE PROFESSORES DE LÍNGUAS E LITERATURAS ESTRANGEIRAS. 3., 1993. Anais... Assis: UNESP, 1993, p. 1-20.

BACHMAN, Lyle. Fundamental considerations in language testing. Oxford: Oxford University Press, 1990.

BORTONI-RICARDO, Stella M. The urbanization of rural dialect speakers: a sociolinguistic study in Brasil. 1985. 265 f. Tese (Doutorado em Letras) - Cambridge University Press: Cambridge, London, 1985.

; DETTONI, Rachel do V. Diversidade lingüísticas e desigualdades sociais: aplicando a pedagogia culturalmente sensível. In: COX, Maria Inês; ASSIS-PETERSON, Ana Antônia. Cenas de sala de aula. Campinas: Mercado de Letras, 2001, p. 81-104.

. Educação em língua materna: a sociolingüística na sala de aula. São Paulo: Parábola Editorial, 2004.

CANALE, Michael; SWAIN, Merryl. Theoretical bases of communicative approach to second language teaching and testing. Applied Lingusitics, v. 1, p. 1-11, 1980.

DALINGHAUS, Ione V. Alunos brasiguaios em escola de fronteira Brasil/Paraguai: um estudo linguístico sobre aprendizagem do português em Ponta Porá, MS. 2009, 148 f. Dissertação (Mestrado em Letras) - Programa de Pós-Graduação em Letras, Universidade Estadual do Oeste do Paraná, Cascavel, 2009.

DOEBBER, Ana Paula. Traços da língua maternal vernacular no contexto escolar. 2006. 180 f. Dissertação (Mestrado em Letras) - Programa de Pós-Graduação em Letras, Universidade Estadual do Oeste do Paraná, Cascavel, 2006. 
ERICKSON, Fred. Ethnographic description. Sociolinguistics. Berlim/ New York: Walter de Gruyter, 1988.

Qualitative methods. In: FINS, R.; ERICKSON, F. (Eds.). Research in teaching and learning. New York: MacMillan Publishing Company, 1990, p. 77-194.

Prefácio. In: COX, Maria Inês, P.; ASSIS-PETERSON, Ana Antônia de. (Orgs.). Cenas de sala de aula. Campinas: Mercado de Letras, 2001, p. 9-17.

GUMPERZ, John J. Hindi Punjabi code switching in Delhi. In: INTERNATIONAL CONGRESS OF LINGUISTICS, 9. Proceedings... p.137-152, 1964a.

Linguistics and social intraction in two communities. In: GUMPERZ, John J.; HYMES, Dell. (Ed.). The ethnography of communication. Washington: D. C. American Anthropological Association, 1964b, p. 137-154.

A sociolinguística interacional no estudo da escolarização. In: COOK-GUMPERZ, Jenny (Org.). A construção social da alfabetização. Porto Alegre: Artes Médicas, 1991, p. 58-82.

Convenções de contextualização. In: RIBEIRO, Branca T.; GARCEZ, Pedro M. (Orgs.). Sociolinguística interacional: antropologia, linguística e sociologia em análise do discurso. Porto Alegre: AGE Ed., 1998, p. 98-119.

LABOV, William. Field methods of the project on linguistic change and varation. In: BAUGH, J.; SHERZER, J. (Eds.). Language in use. NJ: Prentice-Hall, 1986. p. 28-53.

HEYE Jürgen. Sobre o conceito de diglossia. In: GORSKI, Edair M.; Coelho, Izete L. (Orgs.). Sociolinguística e ensino: contribuições para a formação de professores de língua. Florianópolis: Ed. UFSC, 2006. p. 69-83.

HYMES, Dell. On communicative competence. In: PRIDE, J. B.; HOLMES, J. (Eds.). Sociolinguistics Harmondsworth. England: Penguin Books, 1967, p. 269-294.

The ethnography of speaking. In: FISHMAN, J. (Ed.). Reading in the sociology of language I. Mouton: The Hague, 1972. p. 99-138.

MEZAVILA, Albertina. Ucranianos em Cascavel: a história, a religião e a língua. 2007. 180 f. Dissertação (Mestrado em Letras) - Programa de Pós-Graduação em Letras, Universidade Estadual do Oeste do Paraná, 2007.

MOURA, Maria Lourdes de. A representação dos ouvintes sobre o desenvolvimento do estudante surdo e as implicações na/pela linguagem. 2006. 203 f. Dissertação (Mestrado em Letras) - Programa de Pós-Graduação em Letras, Universidade Estadual do Oeste do Paraná, Cascavel, 2006. 
PARANÁ. CELEM. Resolução n 3.546/1986, Instrução Secretarial no Artigo $7^{\circ}$ da Resolução n 3.546/1986, de 15 de agosto de 1986.

PHILIPS, Susan U. Algumas fontes de variabilidade cultural na ordenação da fala. In: RIBEIRO, Branca T.; GARCEZ, Pedro M. (Orgs.). Sociolinguística interacional: antropologia, lingüística e sociologia em análise do discurso. Porto Alegre: AGE Ed., 1998, p. 16-30.

SALES, Adriana O. Planejamento e política linguística: o caso de uma escola indígena em Dourados, MS. 2010. 120 f. Dissertação (Mestrado em Letras) - Programa de Pós-Graduação em Letras, Universidade Estadual do Oeste do Paraná, Cascavel, 2010.

TARALLO, Fernando. Pesquisa sociolinguística. 2. ed. São Paulo: Ática, 1986.

TEIS, Denize T. A (re)construção da identidade do aluno brasiguaio. 2004. 140 f. Dissertação (Mestrado em Letras) - Programa de Pós-Graduação em Letras, Universidade Estadual do Oeste do Paraná, Cascavel, 2004.

TEIS, Mirtes A. Escrita e letramento com alunos Avá-Guarani: aulas de reforço. 2007. 175 f. Dissertação (Mestrado em Letras) - Programa de Pós-Graduação em Letras, Universidade Estadual do Oeste do Paraná, Cascavel, 2007.

VON BORSTEL, Clarice N. Aspectos do bilinguismo: alemão/português em Marechal Cândido Rondon, Paraná, Brasil. 1992. 185 f. Dissertação (Mestrado em Letras) - Curso de Letras, Universidade Federal de Santa Catarina, Florianópolis, 1992.

. Estudo do uso da vibrante no português do Brasil e a aplicabilidade na alfabetização. Revista da JELL - Jornada de estudos linguísticos e literários, Unioeste - Campus de Marechal Cândido Rondon, v.1, p. 2634, 1998.

. Contato linguístico e variação em duas comunidades bilíngues do Paraná. 1999. 202 f. Tese (Doutorado em Linguística) - Curso de Letras, Universidade Federal do Rio de Janeiro, Rio de Janeiro, 1999.

; KLEIN, João Carlos; HITZ, Nilse D. Cenas da escrita: indícios de transferências linguísticas orais. $5^{a}$ Jornada de estudos lingüísticos e literários, 5., 2002. Anais... Marechal Cândido Rondon: Unioeste, 2002. p. 88-100.

Sociolingüística: abordagens quantitativa e qualitativa. Línguas \& Letras, Cascavel, v. 1 e 2, n. 6 e 7, p. 165-172, 2002/2003.

A linguagem sociocultural do Brasildeutsch. São Carlos: Pedro \& Paulo Editores, 2011. 
Um estudo sobre os traços do talian na etnografia escolar. In: VON BORSTEL, Clarice N.; COSTA-HÜBES, Terezinha da C. (Orgs.). Linguagem, cultura e ensino. Cascavel: EDUNIOESTE, 2011, p. 33-48. 